\title{
HLA-DR53 molecules restrict glutamic acid decarboxylase peptide presentation to T cells of a Type I diabetes patient: specification of the trimolecular HLA-peptide/T-cell receptor complex
}

\author{
C. Huck ${ }^{1}$, J. Endl ${ }^{2}$, T. Walk ${ }^{3}$, E. Noessner ${ }^{1}$, G. Jung ${ }^{3}$, R. Wank ${ }^{4}$, D.J. Schendel ${ }^{1}$ \\ ${ }^{1}$ Institute of Molecular Immunology, GSF National Research Centre for Environment and Health, Munich, Germany \\ ${ }^{2}$ Roche Diagnostics GmbH, Penzberg, Germany \\ ${ }^{3}$ Institute of Organic Chemistry, University of Tübingen, Tübingen, Germany \\ ${ }^{4}$ Institute of Immunology, University of Munich, Munich, Germany
}

\section{Abstract}

Aims/hypothesis. Our aim was to define the molecular specificity of glutamic acid decarboxylase-specific T-cells isolated from a patient (patient 40 ) with recent onset Type I (insulin-depent) diabetes mellitus.

Methods. The peptide epitope was defined using synthetic peptides to identify the minimal sequence required for T-cell activation and to determine the amino acids that contribute either to $\mathrm{MHC}$ binding or Tcell receptor signaling. The MHC class II-restricted peptide presentation was determined using a panel of allogeneic antigen-presenting cells and murine fibroblast-cell lines transfected to express individual human class II alleles and by blocking studies with monoclonal antibodies. The T-cell receptor was also molecularly characterized.

Results. Despite that patient 40 carries high-risk alleles of the $D R B 1$ and $D Q B 1$ loci, his T-cells recognize a glutamic acid decarboxylase-derived peptide in association with class II, DR53, molecules. Al- though anchor residues for DR53 molecules have not yet been determined, it was possible to model epitope binding based on sequence comparisons with other class II molecules associated with susceptibility or protection for Type I diabetes.

Conclusion/interpretation. The complete molecular specification of the MHC-peptide ligand and the Tcell receptor complex of glutamic acid decarboxylase-specific T-cells will enable analysis of strategies designed to alter T-cell function. For example, the role of altered peptide ligands or T-cell receptor-specific peptides can be studied using a model whose components reflect the natural affinities of MHCpeptide and T-cell receptor-ligand interactions selected in response to this important autoantigen. [Diabetologia (2001) 44: 70-80]

Keywords Autoimmunity, HLA-DR53, T-cell receptor, T-cell response, Type I diabetes, glutamic acid decarboxylase.
Type I (insulin-dependent) diabetes mellitus is an autoimmune disease that is characterized by the specific destruction of the insulin-producing beta cells in the islets of Langerhans. Susceptibility to Type I diabetes

Received: 3 May 2000 and in revised form: 31 August 2000

Corresponding author: D.J. Schendel, Institute of Molecular Immunology, GSF National Research Center for Environment and Health, Marchioninistrasse 25, 81377 Munich Germany Abbreviations: APC, antigen presenting cells; GAD, glutamic acid decarboxylase; mab, monoclonal antibody; NOD, nonobese diabetic; PBMC, peripheral blood mononuclear cells; PCR, polymerase chain reaction; SI, stimulation index; TCL, T-cell line; TCR, T-cell receptor. is genetically controlled and, as in many other autoimmune diseases, there is a strong risk associated with inheriting specific alleles of the $H L A-D R B 1$ and $D Q B 1$ loci of the MHC [1-4]. These loci encode one polypeptide chain of class II heterodimers that bind and present antigenic peptides to $\mathrm{CD}^{+}{ }^{+} \mathrm{T}$ lymphocytes. Whereas T-cells bearing T-cell receptors (TCR) that recognize self-peptides are often found in the peripheral repertoire, they are normally quiescent. In the situation of autoimmune disease, such self-reactive T-cells become autoaggressive and mediate pathologic responses. Characterization of the MHC-peptide and TCR interactions that are associated with the development of Type I diabetes could 
be useful for generating new diagnostic and therapeutic strategies. Several beta-cell autoantigens have been identified as disease targets by detecting autoantibodies and T-cell responses in Type I patients. More than $80 \%$ of prediabetic people and patients with most recent onset of Type I diabetes have autoantibodies directed against glutamic acid decarboxylase (GAD) and more than $50 \%$ of recent-onset patients have T-cell responses to GAD [5-7]. The GAD-specific T-cells are thought to be involved, at least indirectly, in mediating pathogenic beta-cell destruction. The characterization of such cells is therefore of great interest. A major problem in analysing autoreactive T-cells is their extremely low frequency in the peripheral blood of patients and attaining $\mathrm{T}$ cell infiltrates from the pancreas is rarely feasible $[8,9]$. It is difficult to isolate members of this very small peripheral repertoire of GAD-specific T-cells therefore little is known about T-cells that contribute to pathogenesis in humans. Despite these difficulties, it has been possible to establish several GAD-specific T-cell lines (TCL) or clones from the peripheral blood mononuclear cells (PBMC) of several patients with recent onset Type I diabetes [10]. In our patient-case study we have been able to molecularly define the specific HLA-peptide complex recognized by a GAD-specific T-cell line and its clonal derivatives. Recognition of MHC-peptide ligands by T-cells is usually associated with a restricted TCR repertoire. Restricted TCR alpha and beta gene usage has been described previously in immune responses associated with several autoimmune diseases, including Type I diabetes [8,9], multiple sclerosis [11-14], rheumatoid arthritis [15-17] and psoriasis [18]. The TCRAV and $T C R B V$ chain usage was assessed in the GAD-specific TCL and the TCR receptor alpha and beta sequences of individual T-cell clones were also determined, enabling the complete molecular specification of all components of the trimolecular HLA-peptideTCR complex to be made.

\section{Subjects and methods}

Subjects. Patient 40 was hospitalized at the Academic Hospital, München-Schwabing and Type I diabetes was defined on the basis of a clinical diagnosis. The patient had ketone bodies in the urine, a body mass index below 25 and has been dependent on insulin since he was diagnosed [10]. Molecular HLA class II typing of the patient and allogeneic normal control donors was done using sequence-specific oligonucleotides after DNA amplification with $H L A-D R B 1-, D R B 4-, D Q A 1-$ and $D Q B 1$-specific primers, as used in the $11^{\text {th }}$ International Histocompatibility Workshop [19]. The HLA-DR53 expression for donors Kp89 and Kp143 was made by classical HLA serotyping only because material was not available for molecular characterization.

Antigens. Recombinant human 65kD GAD (hGAD65), expressed in the Baculovirus system, was purchased from Synec- tics (Stockholm, Sweden). The endotoxin content of this preparation was below $0.3 \mathrm{EU} / \mathrm{ml}$, as determined in the Limulus lysate assay. For initial determination of peptide specificity a set of 57 20-mer oligopeptides was used with overlaps of 10 amino acids, spanning the entire protein, and one N-terminal 15-mer peptide. A set of 13-mer peptides that carried alanine or glycine substitutions at each position ("ala-scan" peptides) was used to determine amino acid positions of the minimal epitope influencing HLA and TCR binding. Synthesis was carried out on Fmoc amino acid Wang resin using a robot system for simultaneous multiple solid phase peptide synthesis (SMPS 350; Zinsser Analytic, Frankfurt, Germany). The purity of peptides was confirmed by electrospray mass spectrometry (API III triple quadrupole ion-spray mass spectrometer; Sciex, Ontario, Canada). If necessary, peptides were purified further by preparative HPLC to a purity of at least $95 \%$.

Generation of T-cell line and clones. All cell cultures were set up in RPMI medium containing 5 to $10 \%$ human serum, pooled from male donors. The TCL 40/2 was generated from PBMC of patient 40 using hGAD65 as the stimulating antigen and PBMC as autologous antigen presenting cells (APC) as described previously [10]. Long-term cultures of TCL 40/2 were maintained using as APC the PBMC of Kp3 pulsed with hGAD65 $(5 \mu \mathrm{g} / \mathrm{ml})$ for $3 \mathrm{~h}$ before restimulation made on a weekly basis. The T-cell clones were generated from the TCL $40 / 2$ by limiting dilution, plating 1 or 0.5 cells a well in 96 -well round-bottom plates together with $3 \cdot 10^{4}$ APC from Kp3, pretreated as described above. As a control for some experiments, TCL 6/7 derived from patient 6 was used: this line recognizes GAD peptide p270-283 and is restricted by the DRB1*0401 allele [10].

Proliferation assay. Proliferation assays were made in roundbottomed 96-well culture plates, using $6-10 \cdot 10^{3}$ T-cells and $1 \cdot 10^{5}$ irradiated (40 Gy) autologous or allogeneic PBMC as APC. Antigen (hGAD65 or peptides) was added to the cultures in a final concentration of $5 \mu \mathrm{g} / \mathrm{ml}$, unless indicated otherwise. Mouse fibroblasts transfected with human class II genes [20] were pulsed with different concentrations of GAD-derived peptide and plated in flat-bottomed, 96-well culture plates. After an overnight incubation at $37^{\circ} \mathrm{C}$, the L-cells were irradiated at $100 \mathrm{~Gy}$ before adding $1 \cdot 10^{4} \mathrm{~T}$-cells per well. Data are given as means cpm \pm SD or as stimulation indices (SI) calculated as follows: mean cpm of response to peptide divided by mean cpm with medium only, using duplicate or triplicate measurements as indicated.

Identification of the HLA restriction element. To identify the class II restriction element used for presentation of the GAD peptide, the T-cell clones were probed with a panel of allogeneic APC. Class II molecules that are serologically defined as DR4 or DR7 are composed of alpha chains encoded by the $D R A * 0101$ allele and beta chains encoded by one of several different $D R B 1$ alleles (i.e. $D R B 1 * 0401, * 0402, * 0405$ or $* 0701)$. Class II heterodimers that are serologically defined with DR53-specific antibodies are encoded by the $D R A * 0101$ allele and one of three different alleles $\left(D R B 4^{*} 0101, * 0102\right.$, $* 0103)$ of the $D R B 4$ locus $[21,22]$. The DQ heterodimers are formed by the association of a $D Q A 1$-encoded alpha chain (i.e. $* 0301$ or $* 0501$ ) and a $D Q B 1$-encoded beta chain (i.e. $* 0302$ or *0201).

Blocking experiments. The isotype of class II molecules recognized by the T-cell clones was studied by antibody blocking experiments. The APC $\left(1 \cdot 10^{5}\right.$ cells a well $)$ were first incubated with the various monoclonal antibodies (mab) in different con- 
Table 1. Class II alleles of patient 40 and control donor

\begin{tabular}{llllll}
\hline Subject & Sex & Age & \multicolumn{4}{l}{ HLA class II alleles $^{\text {a }}$} \\
\cline { 3 - 6 } & & & $D R B 1^{\text {a }}$ & $D R B 4^{\text {a }}$ & $D Q A 1^{\text {a }}$ \\
\hline Patient 40 & Female & 54 & $0401 / 0401$ & $0101 / 0101$ & $0301 / 0301$ \\
Control Kp3 & Male & 33 & $0301 / 0401$ & 0103 & $0501 / 0301$ \\
\hline
\end{tabular}

${ }^{a}$ Class II specificities shared between patient 40 and control donor Kp3

centrations for $30 \mathrm{~min}$ at $37^{\circ} \mathrm{C}$. Peptides were then added in a final concentration of $100 \mathrm{nmol} / \mathrm{l}$ and after $3 \mathrm{~h}$ at $37^{\circ} \mathrm{C}$, the APC were irradiated (40 Gy). Further conditions for the proliferation assay were the same as described above.

The Mab-recognizing framework determinants on DR molecules (mab L243) or specifically recognizing $D R B 1 * 0401$ (mab 2ab8) encoded molecules were used to inhibit peptide binding. The murine myeloma protein UPC10 (Sigma, Deisenhofen, Germany) was used as a negative control. All reagents were prepared as purified Ig from hybridoma culture supernatants. The hybridoma for the L243 mab was obtained from the American Type Culture Collection (ATCC; Rockville, Md., USA) and the 2 ab8 hybridoma was generated locally (R. W.).

TCR alpha and beta gene usage. Total RNA was extracted from T-cell lines and clones using the RNAzol B method (CINNA/ BIOTECX, Houston, Tex., USA) and isopropanol precipitation. The RNA was reverse transcribed into first-strand $T C R A V$ and $T C R B V$ cDNA using specific primers [23] and the Superscript preamplification system (BRL, Gaithersburg, Md., USA). Specific amplification of the different $\mathrm{V} \alpha$ and $\mathrm{V} \beta$ genes of the TCR was done using a panel of primers specific for $34 T C R A V$ gene families, and $32 T C R B V$ gene families as the forward primers, and a TCRAC or TCRBC gene specific primer as the reverse primer [23]. The PCR products were directly sequenced using an Autoread sequencing kit of Pharmacia with fluorescence labeled TCRAC and TCRBC primers. For sequencing, the PCR was carried out with biotinylated $T C R A C$ and $T C R B C$ primers [24].

\section{Results}

Mapping of the GAD epitope recognized by T-cell clones. An uncloned T-cell line (TCL 40/2) reactive against the hGAD65 protein was originally isolated from the PBMC of patient 40, obtained at the patient's onset of insulin dependency [10]. We established several clones from TCL 40/2 by limiting dilution using PBMC from a normal control donor (Kp3) as a source of APC (Table 1). Like the parental line, all clones were found to proliferate in the presence of the p556-575 peptide, located in the carboxyterminal region of the protein (Fig.1). Because this 20-mer peptide was not likely to represent the minimal epitope needed for T-cell activation, a series of truncated peptides derived from p556-575 were used to identify the minimal sequence required to activate the T-cell clones. Whereas the four clones varied in their proliferative potential from test to test, they showed remarkably similar patterns of response to the full panel of peptides. Peptides with truncations at the amino-terminal end still allowed full stimulation as long as serine at position 562 was present in the peptide (Fig. 1a, b). Truncation of two further amino acids led to a substantial reduction in proliferation. In additional experiments it was found that removal of only the serine residue at position $562 \mathrm{did}$ not reduce T-cell proliferation compared with peptide p556-575, placing the N-terminal border at position 563 (Fig. 1 and data not shown). Truncation of a single carboxyterminal amino acid led to a strong reduction in the response of all four clones. These results showed that the minimal epitope required to optimally activate these T-cells was p563-575, with the sequence NPAATHQDIDFLI. The identical fine specificity of the four clones suggested that they might represent independent isolates of one single $\mathrm{T}$ cell clone that dominated the TCL 40/2 culture.

GAD specific T-cells show identical TCR. Although a substantial number of limiting dilution cultures was initially established using the PBMC of patient 40, only one independent line which was isolated fulfilled the criteria for GAD-specificity. This indicated that GAD-specific T-cells were extremely rare in the periphery of this patient. In order to determine the Tcell heterogeneity of TCL 40/2, TCR repertoire analysis was carried out to assess how many TCRAV and $T C R B V$ families were expressed by the uncloned population. This analysis revealed that the repertoire of T-cells contributing to this GAD line was extremely limited with only two families (TCRAV2 and $T C R A V 21)$ clearly discerned in the TCR $\alpha$ repertoire and only a single family (TCRBV2) represented in the $\operatorname{TCR} \beta$ repertoire (data not shown). Repertoire analysis showed that amplicons for TCRAV2 and $T C R A V 21$, in addition to $T C R B V 2$, were present in all clones derived from TCL 40/2. These same amplicons were found in T-cells sorted as single cells by flow cytometry as well as in T-cells selected by stringent magnetic bead separation following incubation with a TCRAV2-specific mab (data not shown), clearly showing that both $T C R A V$ sequences were present in individual T-cells.

The TCR alpha and beta amplicons were sequenced to define the functional receptor for these clones. The TCR alpha and beta chains of all four clones had identical CDR3 regions, showing that they were identical isolates of a clonally-expanded T-cell that dominated TCL 40/2 (Table 2). The 

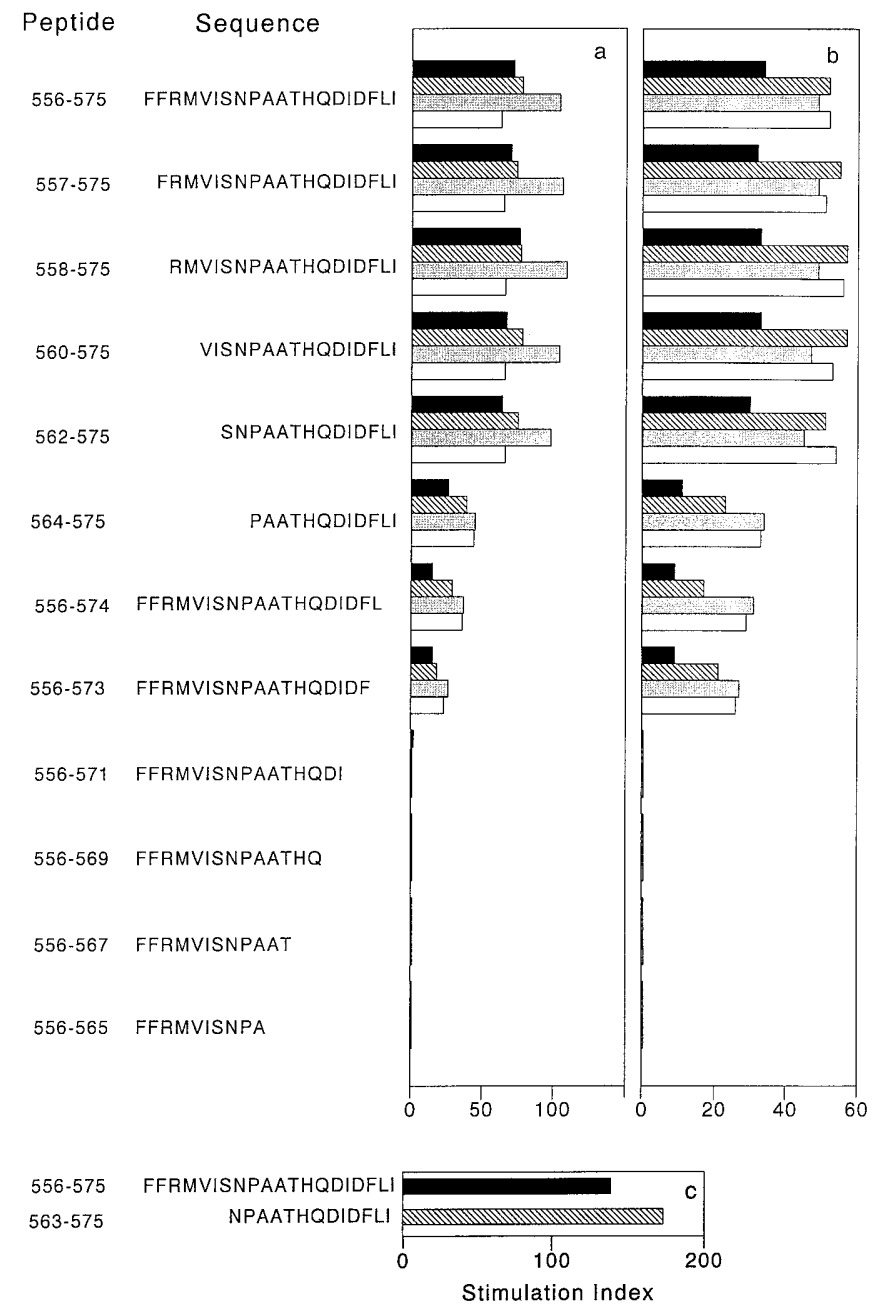

Fig.1. GAD-specific T-cells of patient 40 are optimally activated by a minimal epitope containing the amino acid positions p563-575 of the GAD65 protein. Truncated peptids of the 20-mer GAD epitope p556-575 were used to stimulate the T-cell clones 40/2\#5( $\square), \# 16(\mathbb{N}), \# 21(\square)$ and \#38( $\square)$ in a $72 \mathrm{~h}$ proliferation assay. Dates are given as a stimulation index, calculated by dividing the cpm of radioactive thymidine incorporation in the presence of peptide by cpm in medium alone. The following cpm \pm SD were measured with medium/peptide p556-575 in two independent experiments (a and b), respectively: clone\#5: $434 \pm 31 / 29815 \pm 307$ and $606 \pm 146 / 20556 \pm$ 3490; clone\#16: $756 \pm 138 / 57909 \pm 4$ and $518 \pm 110 / 26948 \pm$ 3992; clone\#21: $673 \pm 55 / 71562 \pm 2739$ and $637 \pm 132 / 31210 \pm$ 572; clone\#38: $1074 \pm 8 / 69280 \pm 1915$ and $671 \pm 107 / 35059 \pm$ 4990. Proliferation of clone 40/2\#38 in the presence of peptides p556-575 and p563-575 is given as SI in c
$T C R A V 2$ gene segment was rearranged in frame to the TCRAJ42 gene segment, whereas the TCRAV21 sequence showed an out of frame rearrangement. Only a single $T C R B V$ rearrangement was detected in the four clones, using the TCRBV2 gene segment rearranged to the TCRBJ1.5 gene segment. Thus, the functional TCR for the four clones used TCRAV2J42 combined with TCRBV2J1.5.

Identification of peptide residues influencing T-cell activation. Present within the minimal GAD peptide p563-575 are amino acids that contribute to MHC binding and others that interact with the TCR; both are necessary for T-cell activation. Variant peptides were synthesized carrying alanine exchanges at all amino acid positions of the minimal sequence p563-575. Those positions that were occupied by alanine in the native peptide were exchanged with glycine. These so called "ala-scan" peptides were pre-incubated with APC from donor Kp3 which were then washed and used to stimulate T-cells in proliferation assays. The results of replicate tests for clone 40/ 2\#38 are shown in Fig. 2. Again, even though the proliferative potential of this clone varied from test to test, the response pattern was very similar. Exchange of alanine for the two terminal residues (NP) at the amino terminus and $\mathrm{L}$ at the carboxy terminus, as well as the internal $\mathrm{H}$ residue, was generally well tolerated whereas exchange for alanine or glycine at all other amino acid positions led to substantial or complete loss of T-cell stimulation. Thus, eight amino acids of this hGAD65 epitope, NPAATHQDIDFLI (underlined) were identified that were essential for T-cell activation, either through their influence on HLA binding or on TCR triggering. Variable influences were noted in repetitive tests when the $\mathrm{N}$ and $\mathrm{C}$ termini were exchanged, indicating that they were supportive but not essential for T-cell activation. The substitution of alanine for these residues did not cause full alteration in the characteristics of the peptide, although some reduction in proliferation was noted occassionally.

Definition of the MHC restriction element for p563-575. Immunophenotyping of the GAD-specific T-cell clones with mab specific for lymphocyte sub-

Table 2. Sequences of TCR alpha and beta chains

\begin{tabular}{|c|c|c|c|c|}
\hline Variable region & CDR3-LOOP & & & Joining region \\
\hline TCRAV2 & $\begin{array}{ccc}\mathbf{C} & \mathbf{A} & \mathbf{V} \\
\text { TGTGCCGTG }\end{array}$ & 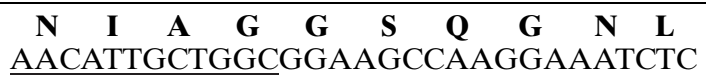 & $\begin{array}{c}\mathbf{I} \quad \mathbf{F} \\
\text { ATCTTT }\end{array}$ & TCRAJ42 \\
\hline$T C R B V 2$ & $\underset{\text { TGCAGTGCT }}{\mathbf{C}} \underset{\mathbf{A}}{\mathbf{A}}$ & 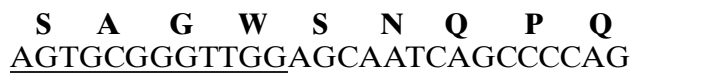 & $\underset{\text { CATTTT }}{\mathbf{H}} \mathbf{F}$ & TCRBJ1.5 \\
\hline
\end{tabular}

Germ-line $\mathrm{V}$ and $\mathrm{J}$ sequences not contributing to the CDR3 loop are noted on the left and right sides, respectively. The CDR3 loop for each sequence is comprised of germ-line encoded amino acids and $\mathrm{N}$ region additions for the TCR alpha and germ-line and N-D-N region encoded amino acids for the TCR beta chain: germ-line nucleotide sequences are given in normal type, $\mathrm{N}$ nucleotides are underlined. Amino acid sequences are given in bold 

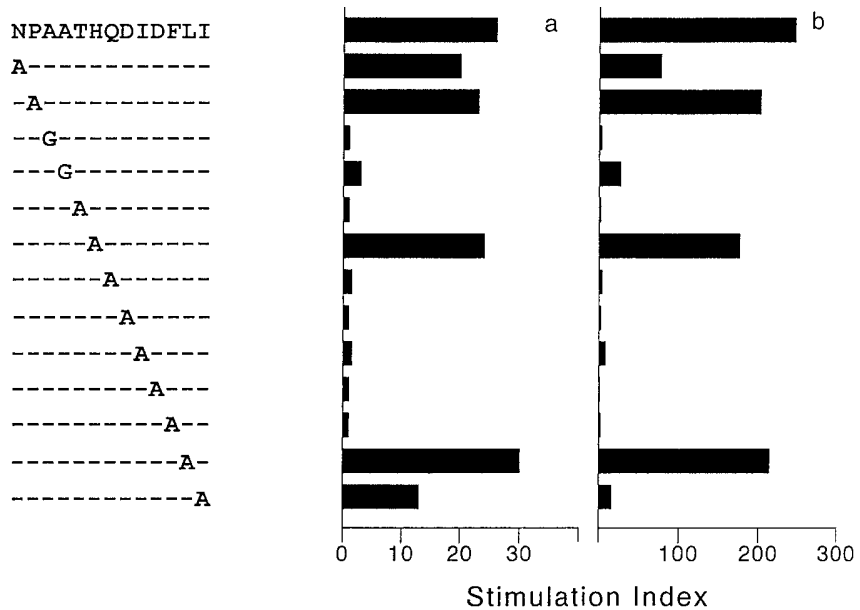

Fig. 2. Definition of the residues contributing to HLA and TCR binding using "ala-scan" peptides. In a proliferation assay, PBMC of the HLA class II matched control donor Kp3 were pulsed with variant peptides of the minimal epitope carrying systematic alanine or glycine substitutions at each position. These peptide-pulsed APC were then used to stimulate the T-cell clone 40/2\#38. Data are given as a stimulation index, calculated as described in Fig. 1. The following cpm \pm SD were measured with medium/peptide p563-575: (a) $683 \pm 89$ / $17974 \pm 1687$ and (b) $385 \pm 29 / 94705 \pm 5172$

sets showed that all clones were of the $\mathrm{CD} 4^{+}$subtype (data not shown). This phenotype indicated that the clones would recognize their antigenic peptides in association with HLA class II molecules, consistent with their activation by externally-pulsed APC. Patient 40 carries $D R B 1 * 0401$ and $D Q B 1 * 0302$ alleles that are associated with an increased risk of Type I diabetes (Table 1). We therefore assumed that molecules encoded by one of these risk-associated alleles would serve as the MHC restriction element for peptide presentation. To evaluate this possibility, we test- ed the proliferation of the clones in response to peptide-pulsed APC derived from unrelated donors that expressed different $D R B 1$ and $D Q B 1$ alleles (Table 3). The APC from donor Kp3, having $D R B 1 * 0401, D Q A 1 * 0301$ and $D Q B 1 * 0302$ alleles in common with patient 40 , strongly stimulated T-cell clone 40/2\#38 in the presence of the peptide p563-575. The APC-expressing class II molecules encoded by the closely related DRB1*0402 (Kp89), *0403 (Kp143) and *0404 (Kp95) alleles were also able to activate the T-cells. Donors Kp89 and Kp95 carried $D Q A 1 * 0301$ and $D Q B 1 * 0302$ alleles but this was not the case for Kp143. Instead, Kp143 shared only the $D Q A 1^{*} 0301$ allele of patient 40 but so did Kp31 whose peptide-pulsed APC failed to induce proliferation. Furthermore, APC of donors Kp79 and Kp86 also induced strong T-cell proliferation, despite their failure to express any shared $D R B 1$, $D Q B 1$ or $D Q A 1$ allele with patient 40 . Several other mismatched APC provided no or only weak stimulation of the T-cells. Thus, the response pattern could not be associated with the sharing of any risk-associated class II molecule.

Earlier studies showed that DQ-specific mab were not able to block proliferation of TCL 40/2, supporting that DQ molecules are not involved in peptidepresentation [10]. Because MHC class II molecules could be promiscuous in their binding and presentation of GAD peptides [25], it seemed feasible that the $D R B 1$ molecules encoded by the various $D R 4$ and $D R 7$ alleles might be capable of presenting the p563-575 epitope. Functional blocking studies were done using a mab specific for DR4 molecules to assess whether they were part of the p563-575 ligand. The APC from donor Kp3 were pre-incubated with the DR4-specific or control mabs, then pulsed with peptide p563-575 for three hours, irradiated and

Table 3. Stimulation of clone 40/2\#38 with allogeneic APC

\begin{tabular}{|c|c|c|c|c|c|c|c|c|c|c|}
\hline \multicolumn{5}{|c|}{ HLA class II alleles $^{\mathrm{a}}$} & \multicolumn{3}{|c|}{ Experiment 1} & \multicolumn{3}{|c|}{ Experiment 2} \\
\hline APC & $D R B 1^{*}$ & $D R B 4^{* \mathrm{~b}}$ & $D Q A 1^{*}$ & $D Q B 1^{*}$ & medium $^{\mathrm{c}}$ & peptide $^{\mathrm{d}}$ & $\mathrm{SI}^{\mathrm{e}}$ & medium $^{c}$ & peptide $^{\mathrm{d}}$ & $\mathrm{SI}^{\mathrm{e}}$ \\
\hline$\overline{\mathrm{Kp} 3}$ & $0401 / 0301$ & positive & $0301 / 0501$ & 0302/0201 & $669 \pm 91$ & $32663 \pm 15129$ & 49 & $265 \pm 1$ & $19075 \pm 1060$ & 72 \\
\hline Kp143 & $0403 / 1501$ & positive & 0301/0102 & $0301 / 0602$ & $419 \pm 73$ & $45009 \pm 2852$ & 107 & $362 \pm 57$ & $9688 \pm 387$ & 27 \\
\hline Kp95 & $0404 / 1001$ & positive & 0301/0101 & $0302 / 0501$ & $382 \pm 6$ & $21388 \pm 3930$ & 60 & $373 \pm 123$ & $4906 \pm 571$ & 132 \\
\hline Kр79 & $0701 / 1301$ & positive & $0103 / 0201$ & $0201 / 0603$ & $1248 \pm 711$ & $43767 \pm 9893$ & 35 & $534 \pm 101$ & $10443 \pm 1553$ & 20 \\
\hline Kp86 & $0701 / 0101$ & positive & $0101 / 0201$ & $0201 / 0501$ & $1718 \pm 329$ & $68250 \pm 1013$ & 40 & $763 \pm 98$ & $20056 \pm 4361$ & 26 \\
\hline Kp35 & $0301 / 1501$ & negative & $0102 / 0501$ & $0201 / 0602$ & & & & $364 \pm 28$ & $371 \pm 205$ & 1 \\
\hline Kр51 & $1301 / 1502$ & negative & 0103/0103 & $0603 / 0603$ & & & & $326 \pm 99$ & $279 \pm 163$ & 0 \\
\hline
\end{tabular}

${ }^{a}$ Class II specificities shared between patient 40 and control donors are highlighted in boldface

$\mathrm{b}$ The presence of DR53 molecules was established by serology and/or molecular typing. Donors Kp3, Kp89, Kp143, Kp95, Kp79, Kp86 were DR53 positive and Kp20, Kp31, Kp35 and $\mathrm{Kp} 51$ were found to lack DR53 expression. At the molecular level Kp3 has a $D R B 4^{*} 0103$ allele and Kp95, Kp79 and Kp86 were found to have $* 0101$ alleles
${ }^{\mathrm{c}}$ Data are given as means $\pm \mathrm{SD}$ for duplicate measurements in each experiment

${ }^{\mathrm{d}}$ PBMC were pulsed with $5 \mu \mathrm{g} / \mathrm{ml}$ of peptide $563-575$

e Stimulation index, calculated according to formula in methods 


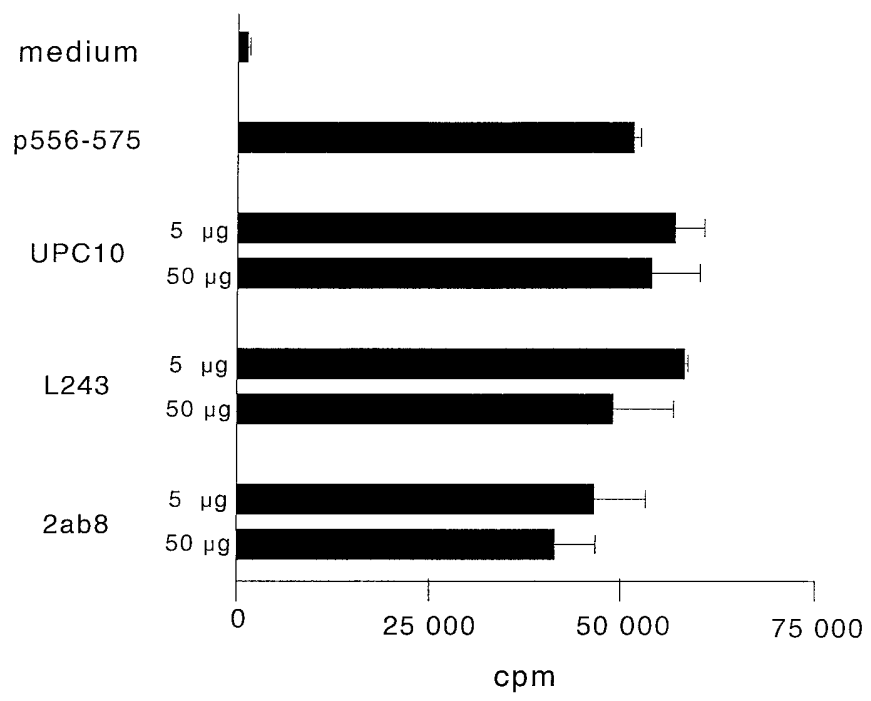

Fig.3. Inhibition of peptide presentation by mabs directed against MHC class II molecules. The proliferative response of T-cell clone 40/2\#38 was measured in the presence of mabs specific for class II molecules. Mab L243 reacts with DRB1-encoded heterodimers of all specificities and mab $2 \mathrm{ab} 8$ reacts with heterodimers with $D R B 1 * 0401$-encoded beta chains. Two concentrations of antibody $(5 \mu \mathrm{g} / \mathrm{ml}$ and $50 \mu \mathrm{g} / \mathrm{ml})$ were evaluated. Data are presented as means $\mathrm{cpm} \pm \mathrm{SD}$. Significant inhibition at $p<0.05$ was not seen with either mab, as compared to the murine myeloma protein UPC10 control and p556-575 in medium alone

Fig. 4A, B. DR53 molecules present the p563-575 GAD peptide. Mouse fibroblast L-cells transfected with the $D R B 1 * 0401$ and $D R A * 0101$ genes (DR4-L-cells) express DR4 molecules at their cell surface and L-cells transfected with the $D R B 4^{*} 0101$ and $D R A^{*} 0101$ genes (DR53-L-cells) express DR53 molecules at their surface. A Clone 40/2\#38 was analyzed in a proliferation assay using peptide-pulsed (p563-575) PBMC from donor Kp3 and both L-cell transfectants as stimulating cells. B The $D R B 1 * 0401$-restricted TCL $6 / 7$ derived from patient 6 (10) was restimulated with GAD peptide p270-283 using PBMC from donor Kp3 and both Lcell transfectants. Data are presented as mean $\mathrm{cpm} \pm \mathrm{SD}$ of replicates

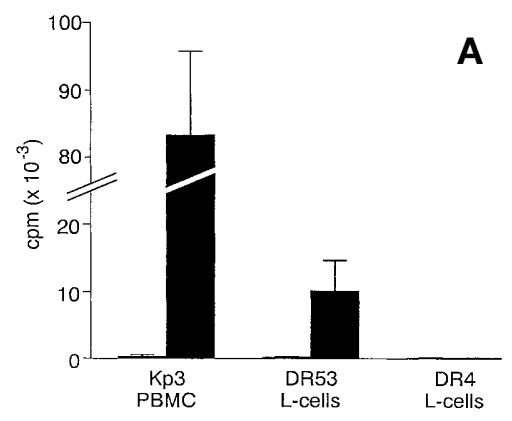

used to restimulate the T-cells. Neither the monomorphic mab, L243, which binds efficiently to most $D R B 1$-encoded molecules nor the DR4-specific mab, 2ab8, was able to significantly inhibit the proliferation of clone 40/2\#38, even at high concentrations, indicating that the DRB1-encoded molecules were not responsible for peptide presentation (Fig. 3).

The MHC haplotypes encoding DR4 and DR7 molecules also carry a common DRB4 sequence that encodes a second DR beta chain. Like $D R B 1$-encoded chains, these $D R B 4$-encoded chains can pair with the $D R A$-encoded alpha chains to form class II heterodimers. This second type of DR molecule binds mabs or alloantisera that have a designated DR53 specificity [21, 22]. Serological or molecular typing of the APC donors showed that all APC capable of stimulating clones 40/2\#38 expressed DR53 molecules, whereas those APC not able to activate the T-cells were DR53 negative (Table 3 ). The molecular subtyping of DR53 showed that three donors whose APC could induce T-cell proliferation, following peptide pulsing, carried $D R B 4^{*} 0101$ alleles in common with patient 40; however, donor Kp3, whose cells were used to maintain the clones in long-term culture, carried a $D R B 4^{*} 0103$ allele (Table 3). Nevertheless, because these two DRB4 alleles have almost identical peptide-binding regions [22], they are probably functionally equivalent. Thus, the response pattern suggested that DR53 molecules might serve as the restriction element for these Tcells.

To test directly whether DR53 molecules were indeed part of the MHC-peptide ligand, we studied the ability of peptide-pulsed mouse fibroblast L-cells to restimulate clone 40/2\#38. Mouse L-cells transfected with the $D R A * 0101$ gene in combination with the $D R B 1 * 0401$ allele express DR4 molecules at the cell surface (DR4-L-cells), whereas cells transfected with $D R A^{*} 0101$ and the $D R B 4^{*} 0101$ allele express DR53 molecules (DR53-L-cells) [20]. Significant proliferation of clone 40/2\#38 was detected following stimulation with peptide p563-575-pulsed DR53-Lcells, whereas no proliferation was detected using the DR4-L-cells (Fig. 4a). Control experiments showed that the DR4-L-cells were capable of activating GAD-specific T-cells using the DRB1*0401-re-

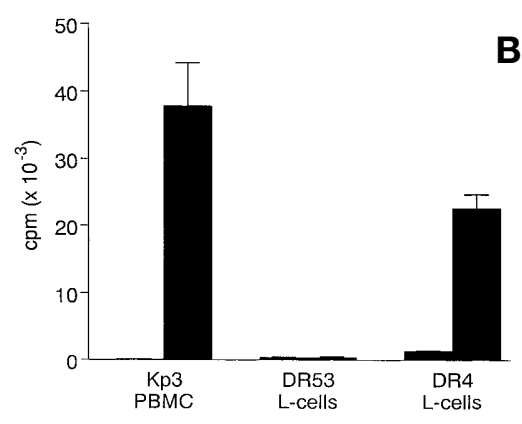


Table 4. Comparison of amino acids 70,71 and 74 in $D R B 1^{\mathrm{a}}$ and corresponding residues in $D R B 4^{\mathrm{b}}$ alleles

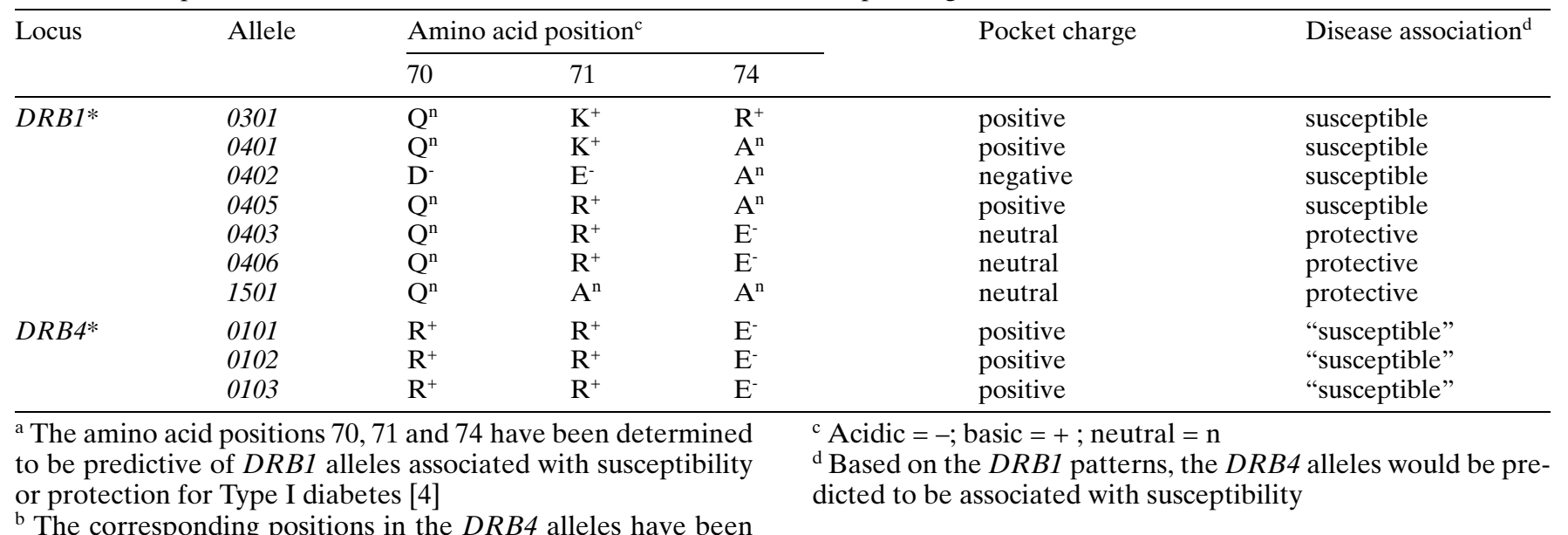
determined by sequence alignment using the IMGT/HLA Sequence Database (www.ebi.ac.uk/imgt/hla/align.html)

stricted TCL 6/7 [10]. Following pulsing with GAD peptide p270-283, a significant proliferative response was measured with the DR4-L-cells but not with peptide-pulsed DR53-L-cells (Fig. 4b).

Responses of T-cells from both patients to the murine L-cells, pulsed with their respective GAD peptides, were much lower than the responses measured using peptide-pulsed PBMC of donor Kp3 as APC. Because L-cells are xenogeneic to human T-cells, optimal interactions do not occur between species-specific adhesion molecules and costimulatory proteins that are required for optimal activation of human $\mathrm{T}$ cells [26].

Considerations regarding DR53-peptide complexes. Alleles of the $D R B 4$ locus have not been reported to be associated with an increased risk of Type I diabetes [1-4]. Recently, however the features of DRB1encoded molecules that contribute to the risk of or protection from Type I diabetes have been reassessed [4]. This analysis showed the importance of the DRP4 pocket; in particular, the charges of amino acids located at positions 70,71 and 74. The DRP4 pockets with a net-positive or net-negative charge due to these three residues were encoded by alleles associated with an increased risk of disease, whereas neutral DRP4 pockets were encoded by alleles associated with protection against disease. If $D R B 4$-encoded molecules fold to form structures similar to $D R B 1$ molecules then the corresponding region in DR53 heterodimers could also be important for peptide selection. We therefore analysed the homologous positions in $D R B 4$-encoded molecules after making sequence alignments with selected $D R B 1$ molecules that are associated with susceptibility for or protection against Type I diabetes (Table 4). Based on our reassessment [4] the net positive charge of the $D R B 1 * 0301-, * 0401$ - and $* 0405$ alleles and the net negative charge of $D R B 1 * 0301, * 0401$ and *0405-encoded molecules and the net negative charge of *0402-encoded molecules confer risk, whereas the balanced charges at positions 71 and 74 produce net neutral pockets in $* 0403$ and $* 0406$-encoded molecules, giving protection. The protection-associated allele $D R B 1 * 1501$ has only neutral residues at these positions. The homologous regions of the DR53 heterodimers, encoded by the three $D R B 4$ alleles, have the features of molecules associated with susceptibility, because the corresponding residues yield a net positive charge in every case.

The peptide-binding motif of DR53 molecules has not yet been determined and only a few peptides that bind to DR53 molecules have been defined. Those peptides known to date are listed in Table 5. An interesting feature of one group of peptides is the presence of one or more negatively charged residues. We speculate that a pocket equivalent to DRP4 in the DR53 heterodimers preferentially accommodates negative residues because of its net positive charge. Based on this, we made a theoretical alignment of these peptides, centering them around the negatively charged residues. Because several of the DR53-binding peptides have more than one negatively charged residue, different registers are feasible. In one alignment, the P4 residue would often have an aliphatic neighbor at position 5 . In a second register, a positively charged residue would often be placed at position 5 .

The first register shown for the GAD p563-575 sequence would be highly compatible with the model for peptides binding to $D R B 1 * 0401$ molecules [32], in which P1, P4, P6, and P7 are embedded deep in the binding groove. Our "ala scan" studies (Fig. 2) showed an influence of all of these residues, with a full loss of function following alanine exchange. Furthermore, the "ala scan" results would support the 
Table 5. Potential alignments of DR53-binding peptides

\begin{tabular}{|c|c|c|c|c|c|c|c|c|c|c|c|c|c|c|c|c|c|c|c|c|c|c|c|c|}
\hline \multirow[t]{2}{*}{ Peptide } & \multicolumn{23}{|c|}{ Peptide register } & \multirow{2}{*}{$\begin{array}{l}\text { Refer- } \\
\text { ence }\end{array}$} \\
\hline & $\overline{-6}$ & -5 & -4 & -3 & -2 & -1 & 1 & 2 & 3 & 4 & 5 & 6 & 7 & 8 & 9 & 10 & 11 & 12 & 13 & 14 & 15 & 16 & $\overline{17}$ & \\
\hline $\mathrm{GAD}_{563-575}$ & $\mathrm{~N}$ & $\mathrm{P}$ & $\begin{array}{l}\mathrm{N} \\
\mathrm{A}\end{array}$ & $\begin{array}{l}\mathrm{P} \\
\mathrm{A}\end{array}$ & $\begin{array}{l}\mathrm{A} \\
\mathrm{T}\end{array}$ & $\begin{array}{l}\mathrm{A} \\
\mathrm{H}\end{array}$ & $\begin{array}{l}\mathrm{T} \\
\mathrm{Q}\end{array}$ & $\begin{array}{l}\mathrm{H} \\
\mathrm{D}\end{array}$ & $\begin{array}{l}\text { Q } \\
\mathrm{I}\end{array}$ & $\begin{array}{l}\mathbf{D}^{-} \\
\mathbf{D}^{-}\end{array}$ & $\begin{array}{l}\mathrm{I} \\
\mathrm{F}\end{array}$ & $\begin{array}{l}\mathrm{D} \\
\mathrm{L}\end{array}$ & $\begin{array}{l}\mathrm{F} \\
\mathrm{I}\end{array}$ & $\mathrm{L}$ & I & & & & & & & & & \\
\hline PDC-E2 ${ }_{163-176}$ & G & $\mathrm{D}$ & $\begin{array}{l}\mathrm{L} \\
\mathrm{G}\end{array}$ & $\begin{array}{l}\mathrm{L} \\
\mathrm{D}\end{array}$ & $\begin{array}{l}\mathrm{G} \\
\mathrm{A} \\
\mathrm{L}\end{array}$ & $\begin{array}{l}\mathrm{D} \\
\mathrm{E} \\
\mathrm{L}\end{array}$ & $\begin{array}{l}\mathrm{L} \\
\mathrm{I} \\
\mathrm{A}\end{array}$ & $\begin{array}{l}\mathrm{L} \\
\mathrm{E} \\
\mathrm{E}\end{array}$ & $\begin{array}{l}\mathrm{A} \\
\mathrm{T} \\
\mathrm{I}\end{array}$ & $\begin{array}{l}\mathbf{E}^{-} \\
\mathbf{D}^{-} \\
\mathbf{E}^{-}\end{array}$ & $\begin{array}{l}\mathrm{I} \\
\mathrm{K}^{+} \\
\mathrm{T}\end{array}$ & $\begin{array}{l}\text { E } \\
\text { A } \\
\text { D }\end{array}$ & $\begin{array}{l}\mathrm{T} \\
\mathrm{T} \\
\mathrm{K}\end{array}$ & $\begin{array}{l}\mathrm{D} \\
\mathrm{I} \\
\mathrm{A}\end{array}$ & $\begin{array}{l}\mathrm{K} \\
\mathrm{T}\end{array}$ & $\begin{array}{l}\text { A } \\
\text { I }\end{array}$ & $\mathrm{T}$ & I & & & & & & 27 \\
\hline PDC-E2 $36-49$ & & $\mathrm{G}$ & $\mathrm{D}$ & $\mathrm{L}$ & $\begin{array}{l}\text { G } \\
\text { I }\end{array}$ & $\begin{array}{l}\mathrm{D} \\
\mathrm{A}\end{array}$ & $\begin{array}{l}\mathrm{L} \\
\mathrm{E}\end{array}$ & $\begin{array}{l}\text { I } \\
\text { V }\end{array}$ & $\begin{array}{l}\mathrm{A} \\
\mathrm{T}\end{array}$ & $\begin{array}{l}\mathbf{E}^{-} \\
\mathbf{D}^{-}\end{array}$ & $\begin{array}{l}\mathrm{V} \\
\mathrm{K}^{+}\end{array}$ & $\begin{array}{l}\mathrm{T} \\
\mathrm{A}\end{array}$ & $\begin{array}{l}\mathrm{D} \\
\mathrm{T}\end{array}$ & $\begin{array}{l}\mathrm{K} \\
\mathrm{V}\end{array}$ & A & $\mathrm{T}$ & $\mathrm{V}$ & & & & & & & 28 \\
\hline OGDC-E2 $2_{100-113}$ & & $\mathrm{D}$ & $\mathrm{E}$ & $\mathrm{V}$ & $\begin{array}{l}\mathrm{D} \\
\mathrm{V}\end{array}$ & $\begin{array}{l}\mathrm{E} \\
\mathrm{C}\end{array}$ & $\begin{array}{l}\text { V } \\
\mathrm{E}\end{array}$ & $\begin{array}{l}\text { V } \\
\text { I }\end{array}$ & $\begin{array}{l}\mathrm{C} \\
\mathrm{T}\end{array}$ & $\begin{array}{l}\mathbf{E}^{-} \\
\mathbf{D}^{-}\end{array}$ & $\begin{array}{l}\mathrm{I} \\
\mathrm{K}^{+}\end{array}$ & $\begin{array}{l}\mathrm{T} \\
\mathrm{T}\end{array}$ & $\begin{array}{l}\mathrm{D} \\
\mathrm{S}\end{array}$ & $\begin{array}{l}\mathrm{K} \\
\mathrm{V}\end{array}$ & $\mathrm{T}$ & $\mathrm{S}$ & $\mathrm{V}$ & & & & & & & 28 \\
\hline NY-ESO-1 $1_{121-136}$ & & & & & & $\mathrm{~V}$ & $\mathrm{~L}$ & $\mathrm{~L}$ & $\mathrm{~K}$ & $\mathbf{E}^{-}$ & $\mathrm{F}$ & $\mathrm{T}$ & $\mathrm{V}$ & $\mathrm{S}$ & G & $\mathrm{N}$ & I & $\mathrm{L}$ & $\mathrm{T}$ & I & $\mathrm{R}$ & $\mathrm{L}$ & $\mathrm{T}$ & 29 \\
\hline L-plastin & $\mathrm{N}$ & $\mathrm{N}$ & A & $\mathrm{K}$ & $\begin{array}{l}\mathrm{N} \\
\mathrm{Y}\end{array}$ & $\begin{array}{l}\mathrm{N} \\
\mathrm{A}\end{array}$ & $\begin{array}{l}\text { A } \\
\text { I }\end{array}$ & $\begin{array}{l}\mathrm{K} \\
\mathrm{S} \\
\mathrm{N}\end{array}$ & $\begin{array}{l}\mathrm{Y} \\
\mathrm{M} \\
\mathrm{N}\end{array}$ & $\begin{array}{l}\mathbf{A}^{\mathrm{n}} \\
\mathbf{A}^{\mathrm{n}} \\
\mathbf{A}^{\mathrm{n}}\end{array}$ & $\begin{array}{l}\mathrm{I} \\
\mathrm{R}^{+} \\
\mathrm{K}^{+}\end{array}$ & $\begin{array}{l}\mathrm{S} \\
\mathrm{K} \\
\mathrm{Y}\end{array}$ & $\begin{array}{l}\mathrm{M} \\
\mathrm{I} \\
\mathrm{A}\end{array}$ & $\begin{array}{l}\text { A } \\
\text { G } \\
\text { I }\end{array}$ & $\begin{array}{l}\mathrm{R} \\
\mathrm{A} \\
\mathrm{S}\end{array}$ & $\begin{array}{l}\mathrm{K} \\
\mathrm{M}\end{array}$ & $\begin{array}{l}\text { I } \\
\text { A }\end{array}$ & $\begin{array}{l}\mathrm{G} \\
\mathrm{R}\end{array}$ & $\begin{array}{l}\text { A } \\
\mathrm{K}\end{array}$ & I & $\mathrm{G}$ & A & & 30 \\
\hline $\operatorname{gliadin}_{1-20}$ & & $\mathrm{~V}$ & $\mathrm{R}$ & $\mathrm{V}$ & $\mathrm{P}$ & $\mathrm{V}$ & $\mathrm{P}$ & $\mathrm{Q}$ & $\mathrm{L}$ & $\mathrm{Q}$ & $\mathrm{P}$ & $\mathrm{Q}$ & $\mathrm{N}$ & $\mathrm{P}$ & $\mathrm{S}$ & $\mathrm{Q}$ & $\mathrm{Q}$ & $\mathrm{Q}$ & $\mathrm{P}$ & $\mathrm{Q}$ & $\mathrm{E}$ & & & 31 \\
\hline $\operatorname{gliadin}_{21-40}$ & & $\mathrm{Q}$ & $\mathrm{V}$ & $\mathrm{P}$ & $\mathrm{L}$ & $\mathrm{V}$ & $\mathrm{Q}$ & $\mathrm{Q}$ & $\mathrm{Q}$ & $\mathrm{Q}$ & $\mathrm{F}$ & $\mathrm{L}$ & G & $\mathrm{Q}$ & $\mathrm{Q}$ & Q & $\mathrm{P}$ & $\mathrm{F}$ & $\mathrm{P}$ & $\mathrm{P}$ & $\mathrm{Q}$ & & & \\
\hline gliadin $_{71-90}$ & & & $\mathrm{P}$ & $\mathrm{Q}$ & $\mathrm{P}$ & $\mathrm{F}$ & $\mathrm{R}$ & $\mathrm{P}$ & $\mathrm{Q}$ & $\mathrm{Q}$ & $\mathrm{P}$ & $\mathrm{Y}$ & $\mathrm{P}$ & $\mathrm{Q}$ & $\mathrm{P}$ & $\mathrm{Q}$ & $\mathrm{P}$ & $\mathrm{Q}$ & $\mathrm{Y}$ & $\mathrm{S}$ & $\mathrm{Q}$ & $\mathrm{P}$ & & \\
\hline gli $\operatorname{adin}_{191-210}$ & & $\mathrm{P}$ & $\mathrm{S}$ & $\mathrm{S}$ & $\mathrm{Q}$ & $\mathrm{V}$ & $\mathrm{S}$ & $\mathrm{F}$ & $\mathrm{Q}$ & $\mathrm{Q}$ & $\mathrm{P}$ & $\mathrm{L}$ & $\mathrm{Q}$ & $\mathrm{Q}$ & $\mathrm{Y}$ & $P$ & $\mathrm{~L}$ & G & $\mathrm{Q}$ & G & $\mathrm{S}$ & & & \\
\hline
\end{tabular}

contention that $\mathrm{P}-2, \mathrm{P}-1, \mathrm{P} 3$ and $\mathrm{P} 5$ would be important TCR contacts because their substitution led to full loss of T-cell proliferation (Fig. 2).

Negative residues are present in only half of the peptides listed in Table 4, thus the remaining peptides can not be directly aligned on this basis. Perhaps, the L-plastin sequence can be accommodated through a neutral alanine residue and an adjacent hydrophobic or, alternatively, positively charged residue. The peptides derived from gliadin are so unique that, at first glance, it does not seem feasible to accommodate them to this model of DR53 binding. A tissue transglutaminase that changes glutamine $(\mathrm{Q})$ to glutamic acid (E), however, is an important autoantigen in celiac disease $[33,34]$ and such deamidated residues have been shown to be critical for binding gliadin peptides to DQ8 molecules [35]. Thus, deamidation of some glutamine residues in the gliadin peptides might provide appropriate acidic residues for DR53 binding.

\section{Discussion}

Glutamic acid decarboxylase represents one of the major autoantigens associated with the development of Type I diabetes in humans [36]. Whereas autoantibodies are prevalent in Type I diabetic patients in the prediabetic stage, it is believed that autoreactive Tcells are pivotal in the pathogenic process that leads to beta cell destruction [37]. From animal studies, $\mathrm{CD}^{+} \mathrm{T}$ helper- 1 cells seem to be essential in initiating the autoaggressive attack, although they alone are not sufficient for causing beta-cell destruction [38-40]. The CD4 T-cell responses of prediabetic people and recent onset diabetic patients have been investigated in vitro using GAD-derived peptides to induce proliferation in PBMC [41, 42]. This approach has allowed several stimulatory peptides to be defined but their processing from intact GAD protein and presentation by APC leading to T-cell induction in patients in vivo remains to be confirmed. We have used an alternative strategy to identify GAD-specific T-cells that could be involved in the development of pathogenic responses. The PBMC of Type I diabetic patients were stimulated with full-length protein, requiring APC processing and presentation to occur in order to achieve T-cell stimulation. Thereafter, we defined the peptide epitopes and MHC-restricting molecules.

In our case study we have molecularly characterized the class II ligand and its complementary TCR for $\mathrm{GAD}$-specific, $\mathrm{CD} 4^{+}$lymphocytes that were isolated from patient 40 . The original T-cell line was established from this patient using a blood sample that was taken within a few days of the time point in which the patient required initial insulin substitution. These GAD-responding T-cells could be classified as Th1 cells based on their secretion of high concentrations of IFN- $\gamma$ in the absence of IL-4 [10]. The four T-cell clones derived from the line were also of the CD4 phenotype and expressed identical TCR alpha and beta chains; thus they represented repetitive isolates of one T-cell clone. As would be expected, all four clones showed specificity for the same minimal peptide (p563-575] and had similar patterns of reponse to the "ala scan" peptides that were used to identify the residues contributing to HLA class II binding and T-cell receptor triggering.

Because patient 40 carried both $D R B 1 * 0401$ and $D Q B 1 * 0302$ alleles that are strongly associated with 
a risk of disease, we expected that these T-cells would recognize the GAD peptide in association with class II molecules encoded by one of these alleles. To our surprise, however, we found that a class II heterodimer with a beta chain encoded by the DRB4 locus served as the restriction element for these T-cells. This was shown by allogeneic APC panel studies and with mab blocking experiments to exclude a role of DRB1-encoded molecules. Earlier studies showed no influence of DQ-specific antibodies on T-cell function [10]; the lack of DQ involvement was further substantiated by our results of the allogeneic APC panel study. A direct involvement of DR53 molecules in peptide presentation was supported by the studies showing that peptide-pulsed DR53 transfected murine L-cells could stimulate the T-cells of patient 40, defining the specific ligand for the T-cell clones. Because the DRB4 locus is present in HLA-DR4, DR7 and DR9 haplotypes [22] and these haplotypes carry different $D R B 1, D Q A 1$ and $D Q B 1$ alleles, they only have the capacity to encode functionally equivalent DR53 heterodimers in common. Thus, the presence of the shared DRB4 locus explains why the GADspecific T-cells of patient 40 were stimulated by allogeneic APC derived from donors having DRB1*0401, *0402,*0403,*0404 and *0701 alleles. Appropriate APC from DR9 donors were not available for comparison.

Few T-cell responses that are restricted by DR53 molecules have been reported; thus the function of $D R B 4$-encoded molecules in antigen presentation is not well understood. Recently, DR53 molecules have been shown to be associated with susceptibility to celiac disease and they were found to bind a surprising number of gliadin-derived peptides [31]. Whereas the majority of gliadin-reactive T-cell clones was reported to be restricted by DQ molecules, Tcells responding to APC derived from DR4 [43] and DR7 [44] donors have also been reported, opening the possibility that they also might recognize some gliadin-derived peptides in association with DR53 heterodimers.

The "ala scan" peptides allowed demarcation of the residues required for MHC-binding and interactions with the TCR. Although we were not able to distinguish those amino acids that serve as HLA anchors from those that make contact with the TCR by direct competitive peptide binding assays, speculations could be made based on the alignment considerations made using $D R B 1 * 0401$-encoded molecules as a model [32]. Several studies have analysed peptides that bind to DR53 molecules [27-31, 45] and a comparison of these sequences revealed some residues that are potential candidates for DR53 binding. Negatively charged residues were characteristic for several peptides; as we suggest, these residues bind in a putative positively charged class II pocket that is equivalent to the DRP4 pocket of DRB1-encoded mole- cules [32]. The DRP4 pocket has been shown to have characteristic features of charge that are associated with susceptibility or protection against Type I diabetes [4]. This same pocket has also been shown to be characteristic for rheumatoid arthritis-associated molecules, whereby a propensity to bind peptides with negatively charged $\mathrm{P} 4$ residues has been correlated with disease risk [46]. Further studies will be necessary to etablish whether our proposed alignment accounts for peptide binding by DR53 molecules.

Although particular $D Q$ alleles confer the highest MHC-linked genetic risk of Type I diabetes, it has not yet been possible to isolate DQ-restricted T-cell lines or clones from Type I patients. To date, only DR heterodimers have been found to restrict GAD peptide presentation to T-cell lines or clones isolated from patients who spontaneously develop the disease. Furthermore, a recent study only found DR-restricted, GAD-specific T-cells in two patients who had congenital rubella and developed Type I diabetes [47]. Nevertheless, a number of DQ-binding peptides have been identified that stimulate T-cells in DQtransgenic mice and some of these peptides have also been shown to induce proliferation in PBMC of Type I patients and control donors carrying $D Q * 0302$ alleles $[42,48]$. Perhaps DQ-restricted Tcell lines or clones are not easily obtained because they develop at different times, are more sequestered in the pancreas, or play a regulatory role that is not adequately assessed by peptide-driven proliferation.

Recent studies showing that GAD protein is the major autoantigen contributing to the development of Type I diabetes in the NOD mouse $[49,50]$ underscores the importance of this autoantigen in the pathogenic process leading to islet-cell destruction. Several GAD epitopes that are presented by $I-A^{g 7}$ encoded molecules have been identified which stimulate T-cells in the NOD mouse $[51,52]$ and, recently, the crystal structure of a GAD peptide/I- $\mathrm{A}^{\mathrm{g} 7}$ complex was determined [53]. In fact, the GAD peptide that we identify here as a component of the DR53-ligand seen by the T-cells of patient 40 was found to bind to $I-A^{g 7}$-encoded molecules of the NOD mouse [53]. The P9 pocket of $I-A^{g 7}$-encoded molecules seems to be critical for peptide binding. The presence of a negatively charged residue in $\mathrm{I}-\mathrm{A}^{\mathrm{g} 7}$-binding peptides appears to compensate for the lack of a charged residue at position 57 in the $\mathrm{P} 9$ pocket. Variations in charge in residue 57 in DQ beta chains, likewise, are associated with susceptibility or protection against Type I diabetes $[54,55]$. The observation that peptide p563-575 can bind to $I-A^{g 7}$-encoded molecules suggests that it might also bind to a human $D Q$ homolog through a negatively charged residue. To date, however, p563-575 has not been identified as a DQ-binding peptide in transgenic mouse studies $[42,48]$ nor by DQ-binding assays [25]. 
Our analyses combined with those of others [5-10, 42] show that multiple epitopes are spread throughout the GAD protein and that different individualized class II peptide ligands characterize the responses in different patients. This case study extends this complexity one step further since it shows that a hitherto unexpected class II heterodimer restricts the response of GAD-specific T-cells. While alleles of $D R B 4$ have not been associated with the risk of Type I diabetes, DR53 heterodimers have structural features that are associated with susceptibility to Type I diabetes as well as for rheumatoid arthritis [46]. Thus, many different GAD-peptide/class II ligands can be formed that have the capacity to activate autoreactive T-cells. Having the complete molecular specification of an HLA-peptide-TCR complex of a GAD reactive T-cell clone opens the possibility to study whether altered peptide ligands or TCR-specific peptides can influence the activity of such T-cells.

Acknowledgements. We thank Dr A.-G. Ziegler of the Diabetes Research Institute, Academic Hospital München-Schwabing, Germany, for providing clinical material and Dr J.P. Johnson, Institute of Immunology, University of Munich for providing the L-cell transfectants. We acknowledge Dr B. Kranz, Institute of Molecular Immunology, GSF, for analysing the TCR surface expression and Dr B. Frankenberger, GSF, for his help in TCR repertoire analyses. Dr E. Albert, Immunogenetics Laboratory, University of Munich is thanked for class II typing of the patient and Kp3.

\section{References}

1. Sheehy MJ, Scharf SJ, Rowe JR et al. [1989) A diabetessusceptible HLA haplotype is best defined by a combination of HLA-DR and HLA-DQ alleles. J Clin Invest 83: 830-835

2. Nepom GT, Erlich H [1991) MHC class-II molecules and autoimmunity. Ann Rev Immunol 9: 493-525

3. McDevitt HO (1998) The role of MHC class II molecules in susceptibility and resistance to autoimmunity. Curr Opin Immunol 10: 677-681

4. Djoulah S, Busson M, Sasazuki T et al. (1999) A new predictive model for insulin-dependent diabetes mellitus susceptibility based on combinations of molecular HLADRB1 and HLA-DQB1 pockets. Tissue Antigens 54: 341-348

5. Atkinson MA, Kaufmann DL, Campbell L et al. (1992) Response of peripheral-blood mononuclear cells to glutamate decarboxylase in insulin-dependent diabetes. Lancet 339: 458-459

6. Harrison LC, Honeyman MC, Deaizpurua HJ et al. (1993) Inverse relation between humoral and cellular immunity to glutamic acid decarboxylase in subjects at risk of insulin-dependent diabetes. Lancet 341: 1365-1369

7. Honeyman MC, Cram DS, Harrison LC (1993) Glutamic acid decarboxylase 67-reactive T-cells: a marker of insulindependent diabetes. J Exp Med 177: 535-540

8. Bottazzo GF, Path MRc, Dean BM et al. (1985) In situ characterization of autoimmune phenomena and expression of HLA molecules in the pancreas in diabetic insulitis. N Engl J Med 313: 353-360
9. Conrad B, Weidmann E, Trucco G et al. (1994) Evidence for superantigen involvement in insulin-dependent diabetes mellitus aetiology. Nature 371: 351-355

10. Endl J, Otto H, Jung G et al. (1997) Identification of naturally processed T-cell epitopes from glutamic acid decarboxylase presented in the context of HLA-DR alleles by T lymphocytes of recent onset IDDM patients. J Clin Invest 99: 2405-2415

11. Ota K, Matsui M, Milford EL, Mackin GA, Weiner HL, Hafler DA (1990) T-cell recognition of an immunodominant myelin basic protein epitope in MS. Nature 346: 183-187

12. Pette M, Fujita K, Wilkinson D et al. (1990) Myelin autoreactivity in multiple sclerosis: recognition of myelin basic protein in the context of HLA-DR2 products by T lymphocytes of multiple-sclerosis patients and healthy donors. Proc Natl Acad Sci USA 87: 7968-7972

13. Joshi N, Usuku K, Hauser SL (1993) The T-cell response to myelin basic protein in familial multiple sclerosis: diversity of fine specificity, restricting elements and T-cell receptor usage. Ann Neurol 34: 385-393

14. Meinl E, Weber F, Drexler K et al. (1993) Myelin basic protein-specific $\mathrm{T}$ lymphocyte repertoire in multiple sclerosis. J Clin Invest 92: 2633-2643

15. Goronzy JJ, Bartz-Bazzanella P, Hu W, Jendro MC, Walser-Kuntz DR, Weyand CM (1994) Dominant clonotypes in the repertoire of peripheral CD4 + T-cells in rheumatoid arthritis. J Clin Invest 94: 2068-2076

16. Walser-Kuntz DR, Weyand CM, Weaver AJ, O'Fallon WM, Goronzy JJ (1995) Mechanism underlying the formation of the T-cell receptor repertoire in rheumatoid arthritis. Immunity 2: 597-605

17. Waase I, Kayser C, Carlson PH, Goronzy JJ, Weyand CM (1996) Oligoclonal T-cell proliferation in patients with rheumatoid arthritis and their unaffected siblings. Arthritis Rheum 39: 904-913

18. Menssen A, Trommler P, Vollmer S et al. (1995) Evidence for an antigen-specific cellular immune response in skin lesions of patients with psoriasis vulgaris. J Immunol 155 : 4078-4083

19. Kimura A, Dong RP, Harada H, Sasazuki TE (1992) DNA typing of HLA class II genes in B lymphoblastoid cell lines homozygous for HLA. In: Tsuji KE, Aizawa ME, Sasazuki TE (eds) HLA 1991: Proceedings of the Eleventh Histocompatibility Workshop \& Conference. Vol 1. Oxford University Press, Oxford, pp 419-425

20. Jacobson S, Sekaly RP, Jacobson CL, McFarland HF, Long EO (1989) HLA class II-restricted presentation of cytoplasmic measles virus antigens to cytotoxic T-cells. J Virol 63: $1756-1762$

21. Lardy NM, van der Horst AR, van den Berg-Loonen EM, Bontrop RE, de Waas LP (1991) Fine specificity of the alloantiserum MSD-51: epitope mapping of HLA-DRw53 determinants. Hum Immunol 32: 65-71

22. Inoko T, Naruse T, Ota M et al. (1997) AHS\# HLA-DR7, DR9, DR53. In: Charron D (ed) Genetic diversity of HLA: Functional and medical implication. Proceedings of the Twelfth International Histocompatibility Workshop \& Conference. Vol 1. EDK, Paris, pp119-128

23. Jantzer P, Schendel DJ (1998) Human renal cell carcinoma antigen-specific CTL: Antigen-driven selection and longterm persistence in vivo. Cancer Res 58: 3078-3086

24. Steinle A, Reinhardt C, Jantzer P, Schendel DJ (1995) In vivo expansion of HLA-B35 alloreactive T-cells sharing homologous T-cell receptors: evidence for maintenance of an oligoclonally donated allospecificity by persistent stimulation with an autologous MHC/peptide complex. J Exp Med 181: 503-513 
25. Harfouch-Hammoud E, Walk T, Otto H et al. (1999) Identification of peptides from autoantigens GAD65 and IA-2 that bind to HLA class II molecules predisposing to or protecting from Type I diabetes. Diabetes 48: 1937-1947

26. Daubenberger C, Lang B, Nickel B, Willcox N, Melchers I (1996) Antigen processing and presentation by a mouse macrophage-like cell line expressing human class II molecules. Int Immunol 8: 307-315

27. Shimoda S, Nakamura M, Ishibashi H, Hayashida K, Niho Y (1995) HLA DRB4 0101-restricted immunodominant Tcell autoepitope of pyruvat dehydrogenase complex in primary biliary cirrhosis: evidence of molecular mimicry in human autoimmune diseases. J Exp Med 181: 1835-1845

28. Shimoda S, van de Water J, Ansari A et al. (1998) Identification and precursor frequency analysis of a common Tcell epitope in mitochondrial autoantigens in primary biliary cirrhosis. J Clin Invest 102: 1831-1840

29. Jager E, Jager D, Karbach J et al. (2000) Identification of NY-ESO-1 epitopes presented by human histocompatibility antigen (HLA-)DRB4*0101-0103 and recognized by CD4(+) T lymphocytes in patients with NY-ESO-1-expressing melanoma. J Exp Med 191: 625-630

30. Kobayashi H, Kokubo T, Yusuke A (1996) Analysis of anchor residues in a naturally processed HLA-DR53 ligand. Immunogenetics 44: 366-371

31. Clot F, Gianfrani C, Babron MC et al. (1999) HLADR53 molecules are associated with susceptibility to celiac disease and selectively bind gliadin-derived peptides. Immunogenetics 49: 800-807

32. Dessen A, Lawrence CM, Cupo S, Zaller DM, Wiley DC (1997) X-ray crystal structure of HLA-DR4 (DRA*0101, DRB1*0401) complexed with a peptide from collagen II. Immunity 7: 473-481

33. Dieterich W, Ehnis T, Bauer M et al. (1997) Identification of tissue transglutaminase as the autoantigen of celiac disease. Nat Med 3: 797-801

34. Molberg O, Mcadam SN, Korner R et al. (1998) Tissue transglutaminase selectively modifies gliadin peptides are recognized by gut-derived T-cells in celiac disease. Nat Med 4: 713-717

35. Sjostrom H, Lundin KE, Molberg O et al. (1998) Identification of a gliadin T-cell epitope in coeliac disease: general importance of gliadin deamidation for intestinal T-cell recognition. Scand J Immunol 48: 111-115

36. Baekkeskov S, Aanstoot HJ, Christgau S et al. (1990) Identification of the $64 \mathrm{~K}$ autoantigen in insulin-dependent diabetes as the GABA-synthesizing enzyme glutamic acid decarboxylase. Nature 347: 151-156

37. Castano L, Eisenbarth GS (1987) Type-I diabetes: a chronic autoimmune disease of human, mouse, and rat. Annu Rev Immunol 8: 647-679

38. Wicker LS, Miller BJ, Mullen Y (1986) Transfer of autoimmune diabetes mellitus with splenocytes from non-obese diabetic (NOD) mice. Diabetes 35: 855-860

39. Bendelac A, Carnaud C, Boitard C, Bach JF (1987) Syngeneic transfer of autoimmune diabetes from diabetic NOD mice to healthy neonates. Requirement for both L3T4 + and Lyt-2 + T-cells. J Exp Med 166: 823-832

40. Kolb H, Kolb-Bachofen V, Roep BO (1995) Autoimmune versus inflammatory Type I diabetes: a controversy? Immunol Today 16: 170-172
41. Lohmann T, Leslie RD, Hawa M, Geysen M, Rodda S, Londei M (1994) Immunodominant epitopes of glutamic acid decarboxylase 65 and 67 in insulin-dependent diabetes melltius. Lancet 343: 1607-1608

42. Herman AE, Tisch RM, Patel SD et al. (1999) Determination of glutamic acid decarboxylase 65 peptides presented by the Type I diabetes-associated HLA-DQ8 class II molecule identifies an immunogenic peptide motif. J Immunol 163: 6275-6282

43. Lundin KEa, Scott H, Fausa O, Thorsby E, Sollid LM (1994) T-cells from the small intestinal mucosa of a DR4,DQ7/DR4,DQ8 celiac disease patient preferentially recognize gliadin when presented by DQ8. Hum Immunol 41: 285-291

44. Franco A, Apella E, Kagnoff MF et al. (1994) Peripheral Tcell response to A-gliadin in celiac disease: differential processing and presentation capacities of Epstein-Barr-transformed B cells and fibroblasts. Clin Immunol Immunopathol 71: 75-81

45. Futaki G, Kobayashi H, Sato K, Taneichi M, Katagiri M (1995) Naturally processed HLA-DR9/DR53 (DRB1*0901/DRB4*0101)-bound peptides. Immunogenetics 42: 299-301

46. Hammer J, Gallazzi F, Bono E et al. (1995) Peptide binding specificity of HLA-DR4 molecules: correlation with rheumatoid arthritis association. J Exp Med 181: 1847-1855

47. Ou D, Jonsen LA, Metzger DL, Tingle AJ (1999) CD4 + and CD8 + T-cell clones from congenital rubella syndrome patients with IDDM recognize overlapping GAD65 protein epitopes. Implications for HLA class I and II allelic linkage to disease susceptibility. Hum Immunol 60: 652-664

48. Liu J, Purdy LE, Rabinovitch S et al. (1999) Major DQ8restricted T-cell epitopes for human GAD65 mapped using human CD4, DQA $1 * 0301$, DQB $1 * 0302$ transgenic Ia ${ }^{\text {null }}$ NOD mice. Diabetes 48: 469-477

49. Tisch R, Yang XD, Singer SM, Liblau RS, Fugger L, McDevitt HO (1993) Immune response to glutamic acid decarboxylase correlates with insulitis in nonobese diabetic mice. Nature 366: 72-75

50. Yoon JW, Yoon CS, Lin HW et al. (1999) Control of diabetes in NOD mice by GAD expression or suppression in $\beta$ cells. Science 284: 1183-1187

51. Zechel MA, Elliott JF, Atkinson MA, Singh B (1998) Characterization of novel T-cell epitopes on $65 \mathrm{kDa}$ and $67 \mathrm{kDa}$ glutamic acid decarboxylase relevant in autoimmune responses in NOD mice. J Autoimmun 11: 83-95

52. Chao C-C, Sytwo H-K, Chen EL et al. (1999) The role of MHC class II molecules in susceptibility to Type I diabetes: identification of peptide epitopes and characterization of the T-cell repertoire. Proc Natl Acad Sci USA 96: 9299-9304

53. Corper AL, Stratmann T, Apostolopoulos V et al. (2000) A structural framework for deciphering the link between I$\mathrm{A}^{\mathrm{g} 7}$ and autoimmune diabetes. Science 288: 505-511

54. Todd JA, Bell JI, McDevitt HO (1987) HLA-DQ beta gene contributes to susceptibility and resistance to insulin-dependent diabetes mellitus. Nature 329: 599-604

55. Kwok, WW, Domeier ME, Johnson ML et al. (1996) HLADQB1 codon 57 is critical for peptide binding and recognition. J Exp Med 183: 1253-1257 